\title{
Care of the Elderly Symposium
}

\author{
Held on 15 September 2010 at the Royal College of Physicians of Edinburgh \\ ML Patterson \\ Specialist Registrar, Department of Medicine, Western General Hospital, Edinburgh, UK
}

DECLARATION OF INTERESTS No conflict of interests declared.
Correspondence to ML Patterson, Department of Medicine, Western General Hospital, Crewe Road, Edinburgh EH4 2XU, UK

tel. +44 (0) 13। 5371000 e-mail morag.patterson@luht.scot.nhs.uk

\section{INTRODUCTION}

The changing demographics of the ageing population have become a familiar concept. Less obvious, perhaps, is the means by which to provide quality care for this growing elderly population in one of the most challenging financial landscapes. 'The silver tsunami' is a phrase depicting the gravity and speed of a dawning new era where the health and social care needs of our elderly demand our attention. This symposium explored a broad range of topics, and held interest for a diverse audience which reflected multidisciplinary working in elderly care.

\section{SESSION I TOPICS IN PARKINSON'S DISEASE}

The symposium opened with a clear focus - the patient. Margo MacDonald (MSP, Scottish Parliament, Edinburgh) is no stranger to healthcare, both in her political career and through living with Parkinson's disease (PD) since 1995. She spoke openly, describing the limitations she faces and how current technologies need to be adapted for people with PD. She promoted physical activity, discussed carer burden and the need to move focus from drug treatments to coping with symptoms. She concluded with her support of the Assisted Dying Bill, citing the evidence recently heard in the Scottish Parliament.

Dr Graeme MacPhee (Consultant and Honorary Clinical Senior Lecturer, Southern General Hospital, Glasgow) followed with an informative overview of the management of non-motor symptoms (NMS) in PD. He described the preponderance of NMS over motor symptoms as PD progresses, the negative impact of NMS on quality of life and the paradoxical focus on motor symptoms. He advocated screening for NMS using the comprehensive self-completed questionnaire 'NMSQUEST' and, drawing attention to the recently published Scottish Intercollegiate Guidelines Network guidelines,' discussed the management of key NMS: depression and anxiety, hallucinations and psychosis, dementia and sleep disorders. Impulse control disorders such as pathological gambling affect up to $14 \%$ of people with PD, and this 'hot topic' drew the first session to a close.

\section{SESSION 2 COMING ONLINE: TELEHEALTH AND OLDER PEOPLE}

Technology plays an ever increasing role in the practice of modern medicine and can enhance access to services, as outlined by Mr James Ferguson (Clinical Director of the Scottish Centre for Telehealth, Aberdeen). Telehealth can separate data collection from interpretation, and uses communication technology to support decision making. With increasing pressure on hospitals, often as a result of 'risk-averse' behaviour, telehealth facilitates the delivery of care in community-centred services.

$\mathrm{Mr}$ Paddy Corscadden (Telecare Development Programme, Edinburgh) presented the telecare options that aim to keep elderly people in their own home while reducing risk and carer burden. Falls detectors have enabled the prompt mobilisation of trained personnel to attend, assess and appropriately refer elderly people who fall at home. However, the evidence for such interventions is lacking, making it more difficult to justify the cost to policy decision makers. Professor Jeremy Wyatt (Director of Institute for Digital Healthcare, Warwick University) addressed this issue by examining the limitations of the current telehealth literature including 'optimism bias', ${ }^{2}$ competing interests and the lack of rigour in systematic reviews.

\section{SESSION 3 FOOD FOR THOUGHT}

The Stanley Davidson lecture was delivered by Professor Sandra Black (Brill Professor of Neurology, University of Toronto, Canada) and examined current thinking in the field of vascular cognitive impairment $(\mathrm{VCl}){ }^{3}$ Vascular dementia is the second most common cause of dementia in the Western world, rises in prevalence with age and shares common risk factors and often coexists with Alzheimer's disease (AD). Small vessel disease is ubiquitous in the ageing population and should not be viewed as benign but as necessitating aggressive risk factor modification. Post-stroke dementia occurs in up to $25 \%$ and should be screened for, with executive function and speed of processing requiring particular attention in $\mathrm{VCl}$. Commonly thought of as treatment only in $A D$, cholinesterase inhibitors may be considered in the treatment of $\mathrm{VCl}$. 
With the focus moving from mind to body, Dr Helen Roberts (Clinical Senior Lecturer in Geriatric Medicine, University of Southampton) echoed the Age UK 2010 campaign 'Still Hungry to be Heard', urging for better recognition and treatment of under-nutrition in the elderly. Malnutrition is common, often gets worse in hospital and is associated with higher mortality. Screening tools such as the Malnutrition Universal Screening Tool (MUST) aid clinical judgement. With little evidence for appetite stimulants, treatment involves focus on dietary intake with mealtime assistance and protein-energy supplements.

Another pressing problem is that of obesity in the elderly, as presented by Professor Mike Lean (Professor of Human Nutrition, University of Glasgow). Obesity, coupled with inactivity, may mask muscle loss resulting in 'sarcopenic obesity'. The clinical consequences of obesity are age-related and can be attenuated by modest weight loss. The effectiveness of diet and lifestyle strategies is not altered with age and, while anti-obesity drugs may be used with caution, very low energy diet (VLED) and bariatric surgery ${ }^{4}$ need further evaluation to establish the risk/benefit ratio.

\section{SESSION 4 ACHIEVING BETTER OUTCOMES AFTER ACUTE AND ELECTIVE GENERAL SURGERY IN OLDER PEOPLE}

The final session examined general surgery in the elderly, providing perspective from different clinicians delivering peri-operative care: the anaesthetist, the general surgeon and the geriatrician. Firstly, Dr Irwin Foo (Consultant Anaesthetist, Western General Hospital, Edinburgh) reviewed the importance of assessing functional reserve including the use of metabolic equivalents (METs), with increased mortality in those unable to attain 4 METs (i.e. climb a flight of stairs). He paid particular attention to dynamic testing such as pre-operative cardiopulmonary exercise testing and intra-operative monitoring techniques such as oesophageal doppler. The benefits of regional over general anaesthesia pertain mainly to orthopaedic surgery; crucial for every elderly patient is identifying the appropriate post-operative care area, with chronological age being no bar to intensive care unit admission.

Mr Mark Potter (Consultant Colorectal Surgeon, Western General Hospital, Edinburgh) highlighted that as more elderly patients undergo surgery, the effect of poor surgical care will be magnified. He described the processes employed to improve care, including the 'surgical pause' and enhanced recovery after surgery (ERAS). Laparoscopic surgery in the elderly is safe, associated with shorter inpatient stays and a more rapid return to pre-operative activities. While outcomes with elective surgery are favourable, emergency surgery is more frequent with advancing age and is associated with a high mortality rate. ${ }^{5}$ Accordingly, non-operative measures such as colonic stents may be used to palliate symptoms or provide a bridge to elective surgery.

The geriatrician's perspective was given by $\mathrm{Dr}$ Jugdeep Dhesi (Consultant Geriatrician, Guy's and St Thomas' NHS Foundation Trust, London) and concluded the session with insight into an alternative model for delivering quality peri-operative care for older patients. Her accompanying review can be found on pages 348-53.

\section{TAKE HOME MESSAGE}

The overriding theme common to the diverse topics covered in this symposium was that the population is getting older. The effects are far reaching and, while not yet completely realised, have already affected many aspects of healthcare. Coverage was also given to the explosion of technology, a facet of change with successes and limitations often raising as many questions as solutions. As the relevance of chronological age blurs, our focus sharpens on the complexities of identifying and delivering quality care for elderly people across all specialties.

\section{REFERENCES}

I Scottish Intercollegiate Guidelines Network. Diagnosis and pharmacological management of Parkinson's disease. Edinburgh: SIGN; 20I0. Available from: http://www.sign.ac.uk/pdf/sign I I3.pdf

2 loannidis JP. Contradicted and initially stronger effects in highly cited clinical research. JAMA 2005; 294:218-28. doi:10.1001/ jama.294.2.218

3 Hachinski V, ladecola C, Petersen RC et al. National Institute of Neurological Disorders and Stroke-Canadian Stroke Network Vascular Cognitive Impairment Harmonization Standards. Stroke 2006; 37:2220-4I. doi:I0.I I6I/0I.STR.0000237236.88823.47

4 Busetto L, Angrisani L, Basso $\mathrm{N}$ et al. Safety and efficacy of laparoscopic adjustable gastric banding in the elderly. Obesity 2008; 16:334-8. doi:10.1038/oby.2007.85

5 Clark AJ, Stockton D, Elder A et al.Assessment of outcomes after colorectal cancer resection in the elderly as a rationale for screening and early detection. $\mathrm{Br} J$ Surg 2004; 91:|345-5I. doi:I0.1002/bjs.460I 